Revista de Derecho YACHAQ

ISSN: 1817-597x (impresa) / ISSN: 2707-1197 (en linea)

Centro de Investigación de los Estudiantes de Derecho (CIED)

Universidad Nacional de San Antonio Abad del Cusco

N. ${ }^{\circ} 10-2019$

[pp. 195-198]

Fecha de recepción: 11/08/19

Fecha de aceptación: 07/09/19

\title{
Tríptico de una dama extraviada
}

\author{
Triptych of a lost lady
}

\section{Martín Agudelo Ramírez ${ }^{[*]}$}

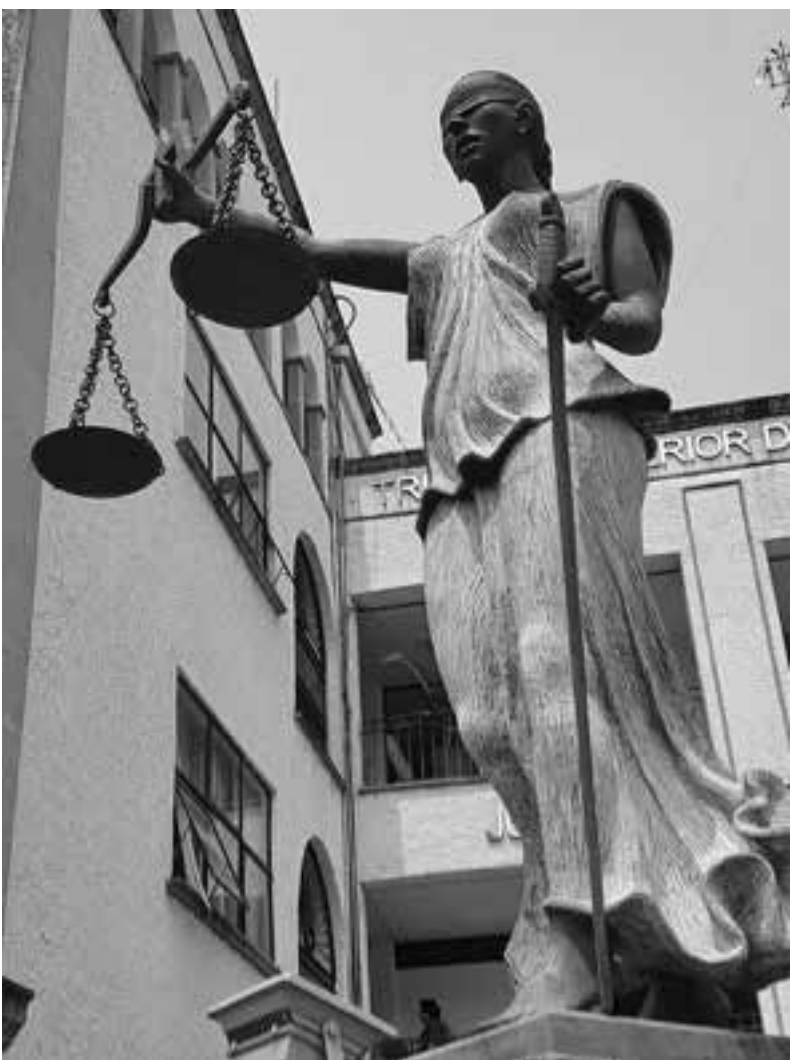

[*] Doctor en Derechos Humanos por la Universidad de Salamanca y en Filosofía por la Universidad Pontificia Bolivariana de Medellín. Miembro de la Red Iberoamericana de Cine Derecho, de Art-Kine y de la Red ALEC. Guionista y realizador audiovisual. Correo: martinagramirez@gmail.com. 
¿Qué está ocurriendo con la Justicia? ¿Qué puede hacerse? Se presenta a continuación el guion de mi cortometraje Tríptico de una Dama Extraviada (2017). El corto es una apuesta intimista sobre la justicia en tiempos de crisis y sobre el dilema que plantea la libertad, con tres partes diferenciadas que se comunican de manera estrecha: iNo huyas, por favor!, La última oportunidad, y Enorme Confusión. Se agradece a José Calvo, profesor de Filosofía del Derecho de la Universidad de Málaga, por la revisión que hizo del guion.

\section{Ficha técnica:}

Guion: Martin Agudelo Ramírez. Música: Daniel Betancur y Jerónimo Betancur. Realizadores: Martín Agudelo Ramírez, Laura Ramos, Santiago Salcedo, Jorge Rondón y Daniel Betancur. Actrices: Laura Isabel Arango (Justicia) y Cristina Zuleta (Libertad). Voz en off: John Viana. Vestuario: Melissa Arenas Sánchez.

\section{iNO HUYAS, POR FAVOR!}

iNo huyas, por favor! Por qué te sientes tan acobardada con el peso de la libertad. iAy, preciosa dama! No quiero que consideres que la libertad es una amenaza. Espero que sigas presente, pero ocupando el espacio que te debe corresponder, y que tu inteligencia no se obnubile por amenazas inexistentes. iNo quiero que te vayas, por favor! Pienso que la libertad puede ayudarte a entender mejor lo que está sucediendo. Solo te pido que la acojas.

iAsí te veo, así te sueño! iNo huyas, por favor! Quiero que seas generosa. Deseo que estés dispuesta a amar la libertad. Quiero que te entregues sin condiciones, sin reservas. iNo temas, mi querida dama! Cuando abraces la libertad, ten certeza que balanza y espada no caerán al piso. Simplemente, quienes reconocen la importancia de tu función te verán un tanto distinta.

¡Arriésgate, te lo pido! No tienes por qué despojarte de tu venda. No te preocupes por la mofa con que muchos quieren ridiculizarte por llevar un trapo que consideran como representación de tus desaciertos por ceguera. Puedes seguir cubierta, si lo consideras necesario para estar en el medio y en lo más alto de la escala ante quienes demandan tus soluciones.

Entiendo que tu causa seguirá siendo el orden a través de decisiones imparciales; no obstante, esto no impide que puedas tocar y sentir con una intensidad estremecedora. Sin lugar a dudas, puedes llegar a experimentar un clímax único, sin que por ello hayas de avergonzarte cuando tus destinatarios conozcan tu dimensión erótica.

iNo te confundas, entusiásmate! Que tengas pasiones y que los demás se enteren de tu actitud incondicional frente al amor no te hace menos grande. Con seguridad que tu áurea divina no desaparecerá, una vez que dejes de ser tan hermética.

iNo huyas, por favor! No te niegues a amar. Solo esto puede redimirte en un mundo que ha perdido la confianza en ti. No dudes de lo único que puede situarte en el ámbito de lo sublime. iEscúchame, noble dama! iAtiende mis ruegos! Esta es tu última oportunidad. iPermíteme que pueda creer en ti!

\section{LA ÚLTIMA OPORTUNIDAD}

Siento que me esquivas. Creo que me odias. Tu pasado escabroso te atormenta. No eres capaz de volver la mirada hacia mí. Parece que no resistes mi gorro de fieltro. Tu rechazo es manifiesto.

Ahora, ¿qué quieres hacer? ¿Escapar? ¿Estás cansada? ¿No comprendes lo valiosa que puedo serte? iQué felices seríamos si nos amáramos! Amar, amar, amar, entregarnos sin reservas, eso quiero, pero... ¿qué sucede? 
iNo quieres nada de mí! No sabes todo lo que puedo hacer por ti si decidieras estar conmigo. Hay quienes me insisten que no siga desperdiciando mi tiempo en una mujer tan desventurada como tú. Deseo, una vez más, seguir tus pasos y abordarte para que comprendas que tu defensa radical del orden te ha enceguecido.

No quiero que la mujer a la que tanto amo sucumba frente a la sinrazón y el despotismo. iTe amo! iTe quiero con pasión! No me importa que los demás te llamen «zorra» y me vituperen por la pasión que siento por ti. iNo me importa! Soy consciente que tocaste fondo, pero aquí estoy. Aún hoy queda tiempo para el perdón. El Nazareno bien lo enseñó al rescatar a la prostituta del oprobio de una sociedad hipócrita.

iVen, ven! No emprendas una retirada definitiva. Puedo despojarme de ese gorro que tanto te incomoda. Al fin y al cabo, ¿qué falta me hace?; tengo clara mi misión. iDeseo abrazarte, que sientas que puedo ofrecerte lo que otros no han sabido darte! iQuédate, por favor! Si dejas que te abrace y te abarque en todo tu ser, te prometo que verás las cosas mejor. No te parece eso suficiente. iNo te abismes en el infierno!

¿Sabes? Me recuerdas tanto a una bella morena de cabeza rapada y de senos voluptuosos, que conocí en Cuernavaca. Al contemplarla me estremecí. No volví a verla, pero ahora que lo pienso, tú te pareces mucho a ella.

iEstás a tiempo! No dejes escapar esta oportunidad única. ¿No entiendes los nuevos signos de los tiempos? Cuando fundamos nuestros cuerpos y espíritus, habrá un acoplamiento perfecto. Sentirás, seguro, un íntimo estremecimiento. ¿No te parece esto fantástico? iAún tienes la oportunidad de ser libre!

Si recapacitas, tendrás toda la capacidad para discernir, y así tu balanza se fijará en el fiel lugar que le corresponde. Aún sueño con un mundo mejor. Con tu enorme inteligencia, haremos todo lo posible para que haya equilibrio y acierto en tus decisiones, sobreponiéndote a lo más mezquino de ese poder hediondo que te degradó.
Eso sí; si decides escucharme y aceptar lo que te propongo, tendrás que dar otro uso a tu espada. Lávala de los restos del fango que la mancharon, para tomar distancia del poder nauseabundo que por tanto tiempo te paralizó. Mas comprende de una vez que sin mí te hundirás.

iEsta es la última oportunidad! Nos necesitamos. iCarpe diem!

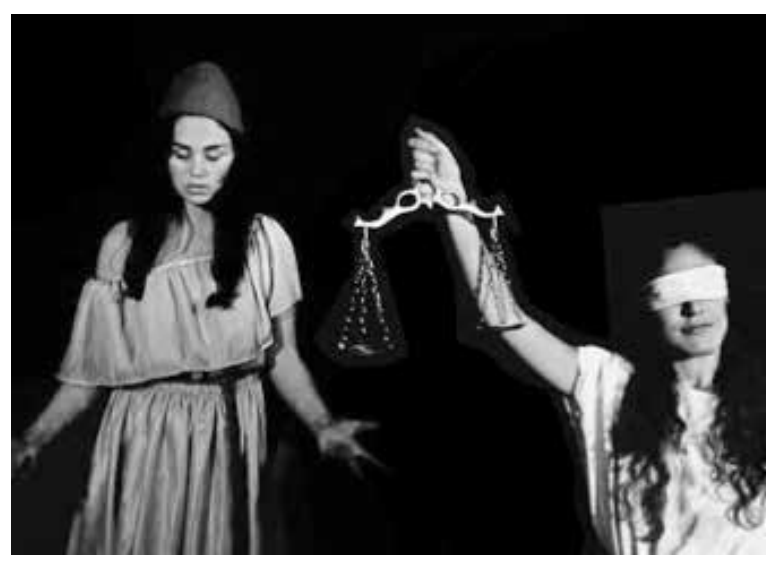

\section{ENORME CONFUSIÓN}

¡Ay, ay, estoy confundida! Siento náuseas. Me siento atrapada en medio del oprobio.

¡Ah, ignominia! ¿Por qué caí en el servilismo?, ¿por qué fui tan estúpida?, ¿por qué no comprendí que me cooptó, desfigurando mi identidad? Sí, sí. Ahora que me miro ante el espejo, y aunque lo hago sin la máscara, siento que no soy como antes.

Estoy cansada de tanta banalidad. Pienso que no tengo nada que hacer en medio de este infierno burocrático que me atrapa y que, lamentablemente, yo misma he consentido. Ya no soy modelo de inspiración para nadie. Deambulo en medio del abismo. No encuentro salidas, salvo huir. Espero que, con el tiempo, a quienes ofendí olviden lo que hice y que fui demasiado banal.

Lo extraño es que todavía haya quien quiera rescatarme. Más increíble aún, porque se trata de una de mis víctimas. Afirma que me quiere 
con pasión, pese a ser tanto el daño como le hice. No entiendo bien sus requerimientos; incluso, me compara con otras mujeres, y asevera que esta es mi última oportunidad. ¿Por qué me habla de amor después de todo el mal que le he hecho? Sí, sí. iQué suplicio! Todo esto es nauseabundo.

iQué tiempos tan difíciles! Permití que en nombre de la estabilidad y la seguridad las libertades individuales se disiparan. Ni siquiera alcanzo a ser una buena consejera.

iAy, querida Antígona! Estoy tan lejos de ti. No soy ni sombra de aquello por lo que ofreciste sacrificio. No tengo la valía tuya para seguir mostrando mi rostro. Mejor sería embozarlo.

Hay alguien que me pretende. Indudablemente, no debe estar en su sano juicio. ¿Por qué insiste que no me vaya? Quiero que entienda que esa insistencia puede conducirle a su pérdida definitiva. ¿Por qué no siente miedo pese a todo el daño que le infligí?

Si me quedo, el monstruo que me ha manoseado por tanto tiempo se interpondrá con seguridad entre nosotros. No hay oportunidad para el amor. Creo que no es posible albergar un espacio para la libertad. iTodo está perdido! No creo que la bestia que me sedujo pueda ser derrotada. Para desdicha de ambas seguirá presente.

iAh qué tozudez! ¿Por qué encuentro a alguien que, en nombre del amor, espera que yo cambie en estos tiempos de crisis? ¿Ahora? No entiendo. ¿Por qué cree que merezco otra oportunidad? y ¿por qué insiste? ¿Será posible? iAh, enorme confusión y desconcierto! ¿Qué estoy diciendo ahora? ¿Y si le fallo?

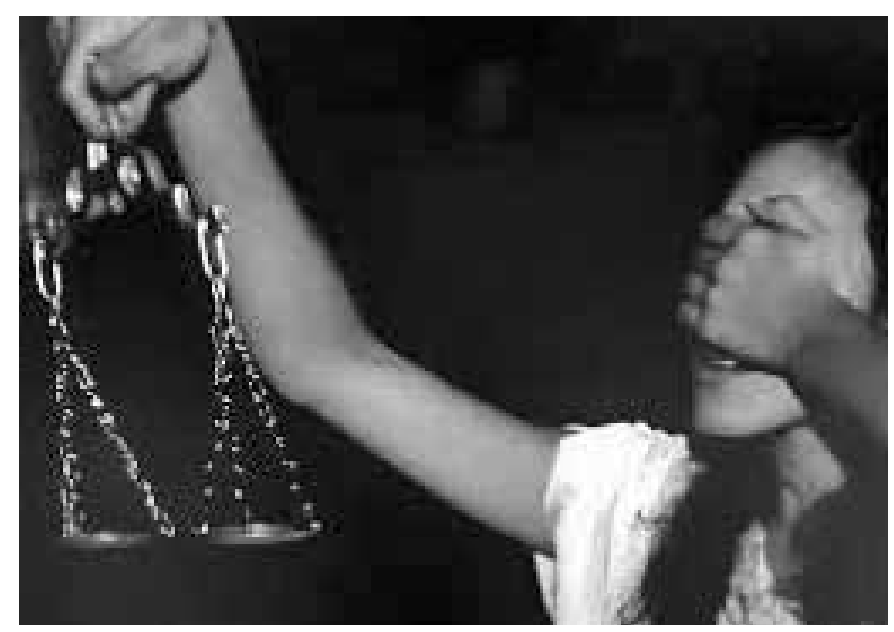

